\title{
Evidence for Association Between Insulin Resistance and Premature Carotid Atherosclerosis in Childhood Obesity
}

\author{
MEHMET EMRE ATABEK, OZGUR PIRGON, AND ALI SAMI KIVRAK \\ Selcuk University, Faculty of Medicine, 42080 Konya, Turkey
}

\begin{abstract}
The present study was undertaken to determine the presence and predictors of the subclinical atherosclerosis in obese children. Fifty obese children [mean age: $11.7 \pm 2.5 \mathrm{y}$, mean body mass index (BMI): $\left.28.2 \pm 4.0 \mathrm{~kg} / \mathrm{m}^{2}\right]$ and 50 age- and sex-matched healthy nonobese controls (mean age: $11.4 \pm 3.73 \mathrm{y}$, mean BMI: $17.6 \pm 3.0 \mathrm{~kg} / \mathrm{m}^{2}$ ) were enrolled in the present study. Oral glucose tolerance test was performed to all obese subjects. Common carotid artery intima-media thickness (IMT) was measured by highresolution B-mode ultrasonography. Carotid artery IMT was significantly increased $(0.0476 \pm 0.007$ versus $0.033 \pm 0.011 \mathrm{~cm} ; p<$ 0.001 ) in the obese group. There were significant relations between carotid artery IMT and insulin sensitivity indexes derived from fasting samples (fasting glucose to insulin ratio (FGIR; $p=0.004, r=-0.404$ ), quantitative insulin-sensitivity check index (QUICK-I; $p=0.002, r=$ $-0.401)$ and homeostasis model assessment of insulin resistance (HOMA-IR; $p=0.034, r=0.300$ ) in the obese group. In a multivariate regression model, QUICK-I emerged as independent correlates for mean IMT in obese children with the total variance explained being $20.7 \%$ ( $\beta=-0.58, p<0.001)$. We concluded that insulin resistance is an independent risk factor for increased carotid artery IMT in obese children. (Pediatr Res 61: 345-349, 2007)
\end{abstract}

A lthough the clinical complications of atherosclerosis such as coronary artery disease and stroke usually occur in middle and late age, autopsy studies have shown that the atherosclerotic process in the vascular wall begins in childhood and is accelerated in the presence of risk factors $(1,2)$. Clustering of cardiovascular risk factors is seen in children and adolescents with the highest degree of insulin resistance suggesting that adult cardiovascular disease is more likely to develop in these young people $(3,4)$. Type 2 diabetes mellitus and metabolic syndrome prevalences among obese adolescents are quite high in the urban area of Konya, central Anatolia. In our previous study, we found that the prevalence of metabolic syndrome was $27.2 \%$ with a significantly higher rate among obese adolescents aged $12-18$ y $(37.6 \%)$ than among obese children aged 7-11 y (20\%) (5).

Increased common carotid artery IMT is significantly related to known cardiovascular risk factors and to carotid plaque, a more advanced atherosclerotic lesion (6). Measuring carotid artery IMT with ultrasonography correlates well with pathologic measurements and is reproducible. Increased carotid artery IMT is correlated with cardiovascular risk factors

Received September 7, 2006; accepted October 24, 2006.

Correspondence: Mehmet Emre Atabek, M.D., Selcuk Universitesi Meram Tip Fakultesi, Cocuk Sagligi ve Hastaliklari, 42080 Konya, Turkey; e-mail: meatabek@ hotmail.com

DOI: $10.1203 / p d r .0 b 013 e 318030 d 206$ and the severity of coronary atherosclerosis and predicts cardiovascular events in population groups $(7,8)$. Carotid artery IMT as a marker of early atherosclerosis has been studied using vascular ultrasonography in children with familial hypercholesterolemia (9), diabetes (10,11), hypertension (12), and childhood obesity $(13,14)$. In a recent study, Zhu et al. found a significant thickening of the intima-media layer in the carotid artery of obese Chinese school children, compared with nonobese controls (15). However, they have not extensively investigated the predictors of increased carotid artery IMT.

Although insulin resistance is a major risk factor for cardiovascular events, only one study has been conducted for a relation between insulin sensitivity indexes and carotid artery IMT in obese children (16). In the present study, we investigated the relationships between carotid artery IMT and insulin sensitivity indices based on fasting samples and OGTT in children with obesity.

\section{METHODS}

Subjects. Fifty children ( 25 girls and 25 boys, mean age: $11.7 \pm 2.5 \mathrm{y}$, mean body mass index (BMI): $28.2 \pm 4.0$ ) were recruited from obese children who attended the outpatient clinic of Pediatric Endocrinology Unit of Selcuk University Hospital in Konya, Turkey. Control subjects ( 25 girls and 25 boys, mean age: $11.4 \pm 3.73$, mean BMI: $17.6 \pm 3.0$ ) were enrolled the study through nonobese healthy children who attended the hospital for minor illness such as common cold, conjunctivitis, short stature, and constipation. After managed in the primary care setting, we collected the blood samples of the control group at the time of the control examination. Obese children were included if they were $8-18$ y age with BMI $\geq 95$ th percentile for age and gender based on the standards of the Centers for Disease Control and Prevention. Children were excluded if they had prior major illness including type 1 or type 2 diabetes, took medications, or had a condition known to influence body composition, insulin action, or insulin secretion (e.g. glucocorticoid therapy, hypothyroidism, Cushing's disease). All subjects were in good health and had normal thyroid function. The study was approved by the local ethics committee of the University of Selcuk. Signed informed consent was obtained for each subject over $12 \mathrm{y}$ of age, and informed parental consent was also obtained for all children regardless of age (Fig. 1).

Each child underwent a complete physical examination, including anthropometric measures. Height and weight were measured in postabsorptive conditions and with an empty bladder. Height was measured to the nearest 0.5 $\mathrm{cm}$ on a standard height board, and weight was determined to the nearest 0.1 $\mathrm{kg}$ on a standard physician's beam scale with the subject dressed only in light underwear and no shoes. The BMI was calculated as weight (in kilograms) divided by height (in meters) squared. The degree of obesity was quantified

Abbreviations: BMI-SDS, body mass index-standard deviation score; FGIR, fasting glucose-to-insulin ratio; HOMA-IR, homeostasis model assessment of insulin resistance; IMT, intima-media thickness; ISI, insulin sensitivity index; OGTT, Oral glucose tolerance test; QUICK-I, quantitative insulin-sensitivity check index 

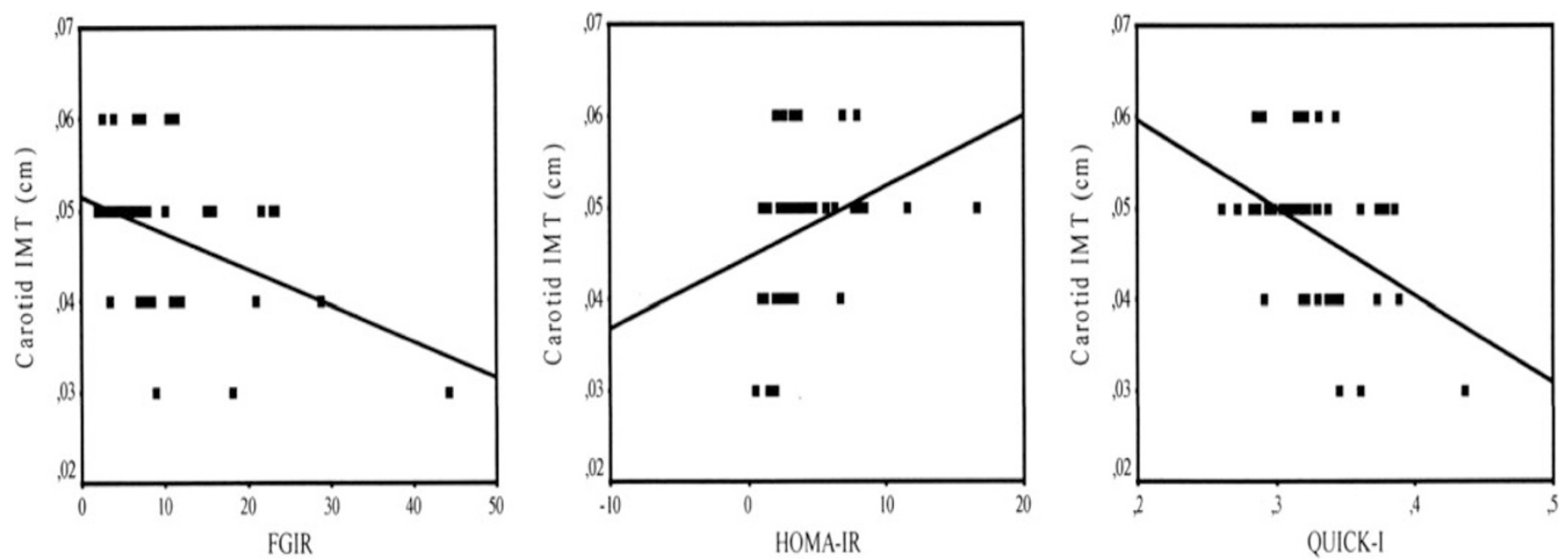

Figure 1. Relationship between carotid artery IMT and insulin sensitivity indexes. FGIR: $r=-0.404, p=0.004$; HOMA-IR: $r=0.3, p=0.034$; QUICK-I: $r=-0.421, p=0.002)$.

using Cole's least mean-square method, which normalizes BMI-skewed distribution and expresses BMI as an SD score (BMI-SDS). This measure gives age- and sex-specific estimates of the distribution median, the coefficient of variation and the degree of skewness by a maximum-likelihood fitting technique (17). Blood pressure was measured with a standard mercury sphygmomanometer after the subjects had rested at least $10 \mathrm{~min}$. Systolic blood pressure (systolic BP) was recorded at the appearance of sounds, and the diastolic blood pressure (diastolic BP) was recorded at the disappearance of sounds.

Blood samples and OGTT. The studies were performed in the morning between 0730 and $0930 \mathrm{~h}$ after the children had fasted overnight. After a 3-d, high-carbohydrate diet $(300 \mathrm{~g} / \mathrm{d})$ and an overnight fast, a standard OGTT $(1.75 \mathrm{~g} / \mathrm{kg}$ or a maximum of $75 \mathrm{~g}$ of glucose) was performed for all subjects except for control group because of the ethical reasons. Venous blood samples were obtained at $0,30,60,90$, and 120 min to measure plasma glucose and insulin levels in the morning by venipuncture after an overnight fasting. After clotting, the serum was separated and immediately explored for analyses. Glucose was determined by the glucose oxidase method. Plasma concentrations of total cholesterol, HDL cholesterol, LDL cholesterol, and triglycerides were measured using a routine enzymatic methods with Olympus 2700 Analyzer (Olympus Diagnostica GmbH, Hamburg, Germany). Insulin levels were measured by an Immulite immunoassay (Diagnostic Products, Los Angeles, CA). Fasting total homocysteine concentrations were determined in EDTA plasma with competitive immunoassay. Samples were separated from the cells, and matched samples were spiked with total homocysteine and then assayed by Immulite 2000 Analyzer (Diagnostic Products). Results were expressed as micromoles per liter. Normal concentrations were 5 and $15 \mu \mathrm{M}$ (18).

Insulin indexes derived from fasting blood samples and OGTT. The HOMA-IR, QUICK-I, and FGIR were derived as estimates of insulin resistance. FGIR was calculated as fasting insulin concentration $(\mu \mathrm{U} / \mathrm{mL}) /$ fasting glucose concentration $(\mathrm{mg} / \mathrm{dL})$. HOMA-IR was calculated as fasting insulin concentration $(\mu \mathrm{U} / \mathrm{mL}) \times$ fasting glucose concentration $(\mathrm{mmol} / \mathrm{L}) / 22.5(19)$. QUICK-I was calculated as $1 /[(\log$ fasting insulin concentration $(\mu \mathrm{U} / \mathrm{mL})+$ log fasting glucose concentration (mg/dL)] (20).

The total plasma glucose response and insulin secretion were evaluated from the area under the response curve (AUC) estimated by the trapezoid rule. The insulin sensitivity index (ISI) proposed by Matsuda and De-Fronzowas calculated as follows: ISI-composite $=10.000 /$ square root of $[$ (mean plasma insulin $\times$ mean plasma glucose during OGTT) $\times$ (fasting plasma glucose $\times$ fasting plasma insulin)] (21).

Ultrasound imaging. The same sonographer, who was blinded to the participant's laboratory values and risk factor levels, did all examinations. Scans were obtained at rest; the subjects were laid quietly for $10 \mathrm{~min}$ before the first scan. High-resolution B-mode ultrasonography of the right common carotid artery was performed with a LOGIQ 9 (GE Healthcare, Milwaukee, WI) with a linear $10-\mathrm{MHz}$ linear transducer. The participants were examined in the supine position with the head turned slightly to the left. Longitudinal images of the common carotid artery were obtained by combined B-mode and color Doppler ultrasound examinations. The IMT of the common carotid artery far wall was measured with the electronic calipers of the machines, as described by Pignoli et al. (22). On a longitudinal, two-dimensional ultrasound image of the carotid artery, the posterior (far) wall of the carotid artery was displayed as two bright white lines separated by a hypoechogenic space. The distance between the leading edge of the first bright line of the far wall and the leading edge of the second bright line indicated the carotid artery IMT. The carotid artery IMT was measured during end diastole. The carotid artery IMT measurements were performed on-line. The mean carotid artery IMT was calculated for each children as the average of three consecutive measurements of maximum far wall thickness obtained from the common carotid artery, $20 \mathrm{~mm}$ below the carotid bulb. The coefficients of variation of the measurements were less than $3 \%$.

Statistical methods. Data were expressed as mean \pm SD. The KolmogorovSmirnov test was applied separately for boys and girls to check the normality of the variables. Differences in the means of variables were tested using both parametric and nonparametric tests depending on the distribution of the variables. Any variables that were not normally distributed were logtransformed before data analysis. Statistical correlation was assessed using the Pearson test $(r)$. Separate relationships between IMT and insulin sensitivity indices (HOMA-IR, FGIR, QUICK-I, and ISI) were also examined after adjustment for age, sex, BMI, BMI-SDS, systolic and diastolic blood pressure, total cholesterol, triglycerides, LDL cholesterol, HDL cholesterol, and total homocysteine using general linear regression models (backward analysis). Statistical significance was taken as $p<0.05$. All statistical analysis was performed using the Statistical Package for Social Sciences (SPSS/Windows version 11·0, SPSS Inc., Chicago, IL).

\section{RESULTS}

The characteristics of the study population are shown in Table 1 . Both the obesity group and control group showed no significant difference in terms of gender composition, age, and body height. Subjects in the obese group had a significantly higher body weight, BMI, BMI-SDS and blood pressure. Total cholesterol, LDL cholesterol, and triglyceride levels were significantly elevated in obese children, whereas HDL was only slightly lower than the controls. The carotid artery IMT of obese children and controls ranged from 0.04 to $0.06 \mathrm{~cm}$ and 0.02 to $0.05 \mathrm{~cm}$, respectively. The obese group had significantly higher carotid artery IMT than the controls $(0.0476 \pm 0.007$ versus $0.033 \pm 0.011 \mathrm{~cm} ; p<0.001)$. The values of total homocysteine in obese group, which were all within normal ranges, were slightly higher than those in controls, but not significantly so $(p=0.053)$.

Table 2 shows the correlations between carotid artery IMT and other measurements in obese children. When IMT was considered as a continuous variable in the whole population of obese children, it was found to be positively correlated in 
Table 1. Characteristics of the study population

\begin{tabular}{|c|c|c|c|}
\hline & $\begin{array}{c}\text { Children } \\
\text { with obesity }\end{array}$ & $\begin{array}{l}\text { Control } \\
\text { children }\end{array}$ & $\begin{array}{c}p \\
\text { value }\end{array}$ \\
\hline Number of subjects (f/m) & $50(25 / 25)$ & $50(25 / 25)$ & - \\
\hline Age (y) & $11.7 \pm 2.5$ & $11.4 \pm 3.73$ & 0.721 \\
\hline Weight $(\mathrm{kg})$ & $64.1 \pm 21.6$ & $38.4 \pm 14.8$ & $<0.001$ \\
\hline Height $(\mathrm{cm})$ & $148.8 \pm 16.1$ & $143.8 \pm 19.8$ & 0.174 \\
\hline $\mathrm{BMI}\left(\mathrm{kg} / \mathrm{m}^{2}\right)$ & $28.2 \pm 4.0$ & $17.6 \pm 3.0$ & $<0.001$ \\
\hline BMI-SDS & $2.03 \pm 0.34$ & $0.42 \pm 0.4$ & $<0.001$ \\
\hline $\begin{array}{l}\text { Systolic blood pressure } \\
\quad(\mathrm{mm} \mathrm{Hg})\end{array}$ & $120.8 \pm 17.6$ & $106.1 \pm 11.8$ & $<0.001$ \\
\hline $\begin{array}{l}\text { Diastolic blood pressure } \\
\quad(\mathrm{mm} \mathrm{Hg})\end{array}$ & $79.3 \pm 11.8$ & $66.4 \pm 9.0$ & $<0.001$ \\
\hline \multicolumn{4}{|l|}{ Lipids } \\
\hline Total ch & $180.2 \pm 27.6$ & $154.3 \pm 26.3$ & $<0.001$ \\
\hline$q^{*}$ & $133.6 \pm 84.1$ & $81.2 \pm 31.7$ & $<0.001$ \\
\hline esterol $(\mathrm{mg} / \mathrm{dL}) \dagger$ & $109.6 \pm 29.3$ & $92.5 \pm 24.3$ & 0.002 \\
\hline HDL c & $47.3 \pm 13.5$ & $48.5 \pm 10.2$ & 0.626 \\
\hline$(\mu \mathrm{mol} / \mathrm{L})$ & $9.8 \pm 3.9$ & $8.3 \pm 3.6$ & 0.053 \\
\hline Carotid artery IMT (cm) & $0.0476 \pm 0.007$ & $0.033 \pm 0.011$ & $<0.001$ \\
\hline $\begin{array}{l}\text { Fasting glucose level } \\
(\mathrm{mg} / \mathrm{dL}) \S\end{array}$ & $97.5 \pm 8.5$ & $88.9 \pm 8.7$ & $<0.001$ \\
\hline $\begin{array}{l}\text { Fasting insulin level } \\
\qquad(\mu \mathrm{U} / \mathrm{mL}) \mathbb{I}^{*}\end{array}$ & $16.0 \pm 11.0$ & $5.8 \pm 4.6$ & $<0.001$ \\
\hline FGIR & $9.6 \pm 7.8$ & $32.5 \pm 46.3$ & 0.001 \\
\hline HOMA-IF & $3.92 \pm 3.0$ & $1.32 \pm 0.95$ & $<0.001$ \\
\hline QUICK-I & $0.32 \pm 0.03$ & $0.39 \pm 0.08$ & $<0.001$ \\
\hline \multicolumn{4}{|l|}{ OGTT derived indexes } \\
\hline $\operatorname{AUC}_{\text {glucose }}(\mathrm{mg} / \mathrm{dL} \times 120 \mathrm{~min})$ & $11754 \pm 1431$ & - & - \\
\hline $\operatorname{AUC}_{\text {insulin }}(\mu \mathrm{U} / \mathrm{mL} \times 120 \mathrm{~min})$ & $6504 \pm 2689$ & - & - \\
\hline ISI & $4.35 \pm 2.52$ & - & - \\
\hline
\end{tabular}

Data are given as mean $\pm \mathrm{SD}$.

$\dagger$ To convert to $\mathrm{mmol} / \mathrm{L}$, multiply by 0.0259 .

$\ddagger$ To convert to $\mathrm{mmol} / \mathrm{L}$, multiply by 0.0113 .

$\S$ To convert to $\mathrm{mmol} / \mathrm{L}$, divide by 18 .

II To convert to pmol/L, multiply by 6.945 .

* Statistical analysis was undertaken on log-transformed variables.

Table 2. Relationship between carotid artery intima media thickness, insulin sensitivity indexes, and the other cardiovascular risk factors in obese children

\begin{tabular}{lcc}
\hline \multicolumn{1}{c}{ Variables } & $r$ & $p$ \\
\hline Weight & 0.159 & 0.202 \\
Height & 0.227 & 0.174 \\
BMI-SDS & 0.20 & 0.893 \\
Systolic blood pressure & 0.172 & 0.233 \\
Diastolic blood pressure & 0.052 & 0.718 \\
Total cholesterol & 0.085 & 0.558 \\
Triglycerides & 0.076 & 0.600 \\
LDL cholesterol & 0.002 & 0.988 \\
HDL cholesterol & -0.120 & 0.405 \\
Total homocysteine & 0.105 & 0.469 \\
Fasting glucose level & 0.167 & 0.247 \\
Fasting insulin level & 0.315 & 0.026 \\
FGIR & -0.404 & 0.004 \\
HOMA-IR & 0.300 & 0.034 \\
QUICK-I $_{\text {AUC }}$ & -0.421 & 0.002 \\
AUC & 0.04 & 0.782 \\
ISI $^{\text {insulin }}$ & 0.029 & 0.843 \\
\hline
\end{tabular}

univariate analysis with fasting insulin level $(r=0.315, p=$ 0.026), HOMA-IR $(r=0.300, p=0.034)$ and negatively correlated with FGIR $(r=-0.404, p=0.004)$, QUICK-I ( $r=$ $-0.421, p=0.002)$, but there was no association with weight $(r=0.202, p=0.159)$, height $(r=0.174, p=0.227), \mathrm{BMI}$
Table 3. Variable independently associated, in an age-, sex-, and other risk factor-adjusted backward multiple linear regression analysis, with the dependent variable carotid artery IMT in obese children

\begin{tabular}{lccr}
\hline & \multicolumn{3}{c}{ Carotid artery IMT } \\
\cline { 2 - 4 } & $r^{2}$ & $\beta$ & \multicolumn{1}{c}{$p$} \\
\hline QUICK-I $^{2}$ & 0.207 & -0.58 & $<0.001$ \\
AUC $_{\text {insulin }}$ & & -0.29 & 0.057 \\
\hline
\end{tabular}

$(r=0.205, p=0.153)$, BMI-SDS $(r=0.2, p=0.893)$, systolic $(r=0.172, p=0.233)$ and diastolic blood pressure $(r=0.052, p=0.718)$, total cholesterol $(r=0.085, p=$ $0.558)$, triglycerides $(r=0.076, p=0.600)$, LDL cholesterol $(r=0.002, p=0.988)$, total homocysteine $(r=0.105, p=$ 0.469), fasting glucose level $(r=0.167, p=0.247)$, $\mathrm{AUC}_{\text {glucose }}(r=0.04, p=0.782), \mathrm{AUC}_{\text {insulin }}(r=0.029$, $p=0.843)$ and ISI $(r=-0.252, p=0.078)$. There were no significant relationships between carotid artery IMT and clinical and laboratory parameters in controls (data not shown).

In the regression analysis, QUICK-I was negatively correlated with increased IMT $(\beta=-0.58, p<0.001)$ even after adjusting for age, sex, BMI, BMI-SDS, systolic/diastolic blood pressure, total cholesterol, triglycerides, LDL cholesterol, HDL cholesterol, and total homocysteine as co-factors with the total variance explained being $20.7 \%$ (Table 3). HOMA-IR, FGIR, and ISI were not significantly correlated with IMT after adjusting for atherosclerotic risk factors.

\section{DISCUSSION}

In this study, we demonstrated the effect of insulin resistance on carotid IMT in obese children. There has been considerable interest in the insulin resistance and cardiovascular disease. Central obesity and the attendant insulin resistance/hyperinsulinemia occurring in childhood are the driving force of the multiple metabolic syndrome $\mathrm{X}$, insulin resistance syndrome, or the "deadly quartet" (23). Therefore, we decided to measure the IMT of common carotid artery in obese children, since an increased IMT is known to be a parameter of atherosclerotic changes and to be detected without obvious abnormalities of the classic vascular risk factors. In the present study, the number of risk factors identified in obese children was associated with increased carotid artery IMT.

Autopsy studies in adolescents and young adults document that atherosclerosis begins in adolescence and that the traditional risk factors are associated with its development (24). Studies on early atherosclerotic changes in children have mainly focused on dyslipidemia, hypertension, obesity, and diabetes as risk factors but not on insulin resistance or importance of the insulin sensitivity indexes. The central role of insulin in the background of the clustering of some cardiovascular risk factors was first suggested by the reports on endogenous hyperinsulinemia and insulin resistance in essential hypertension (25). However, obese children exhibit glucose intolerance, which is strongly associated with evidence of both insulin resistance and impaired insulin secretion (26). Insulin- 
resistant individuals who can compensate by hyperinsulinemia may escape diabetes, but are still prone to other complications, such as early atherosclerosis, progression of obesity (especially central type), acanthosis nigricans, increased skin tags, hypertension, dyslipidemia, hypercoagulation, polycystic ovary syndrome, fatty liver infiltration, focal segmental glomerulosclerosis, as well as increased cancer rate (27). However, few research reports have studied the relations between carotid artery IMT and insulin resistance indexes.

In the present study, fasting glucose was not associated with carotid artery IMT, although fasting insulin was significantly associated with carotid artery IMT in children with obesity. Therefore, these data supported the idea that insulin resistance may have a role in the development of early structural atherosclerotic vascular changes in children with obesity. The ISI and $\mathrm{AUC}_{\text {insulin }}$, derived from the OGTT appear to be useful outcome measures for clinical trials in obese children and adolescents in terms of improving insulin sensitivity and glucose tolerance (28). We did not find a relation between insulin sensitivity indexes (ISI and AUC) derived from OGTT measurements and carotid artery IMT in obese children. Balletshore et al. (16) have also reported that glucose-clamp assessed insulin sensitivity was not correlated with IMT. However, in the present study, conducted in a group of obese children, we showed that insulin sensitivity indexes derived from fasting samples and elevated basal insulin levels were significantly associated with increased carotid artery IMT. We found FGIR and QUICK-I are more significantly related with carotid artery IMT than HOMA-IR.

Carotid artery IMT is affected by many factors including serum lipids. Autopsy studies in children have also shown a significant relationship between serum cholesterol concentration and early atherosclerotic lesions $(1,2)$. Increased carotid artery IMT has previously been demonstrated in children with familial hypercholesterolemia. Case-control studies of children and young adults demonstrate that familial hypercholesterolemia and borderline hypertension are associated with greater IMT (11-13). In the present study, serum lipid levels in obese children were significantly higher than those of healthy subjects. However, we did not find a significant relationship between carotid artery IMT and serum lipids. The reason for this negative result might be owing to fact that our subjects had not very high lipid levels as did in familial hypercholesterolemia. Although, reduction in BMI slows the yearly rate of increase in carotid-wall thickness (29), the thickness of the arterial wall increasing with proportional to BMI is still a matter of debate. In the present study, we also did not find a significant relationship between anthropometric data and carotid artery IMT. The number of subjects is relatively small which might explain these non significant results.

Retrospective and prospective studies have demonstrated that hyperhomocysteinemia is the other risk factor for premature cardiovascular disease independent of other classic risk factors, such as smoking, hypercholesterolemia, arterial hypertension, and diabetes (30-33). Elevated plasma homocysteine has been shown to be a significant risk factor for higher carotid artery IMT (34). However, the other studies from
Davis et al. (35) and Mahoney et al. (36), in the same cohort, did not find plasma homocysteine as a risk factor. These observations suggest that elevated homocysteine levels and lipids may not affect carotid artery IMT at a younger age. In the present study, we demonstrated that homocysteine levels in obese children were slightly higher than healthy subjects and also homocysteine levels was significantly associated with basal insulin levels (data not shown), although we were unable to show a relationship between fasting plasma homocysteine levels and carotid artery IMT. Our data support that plasma homocysteine levels might be a characteristic for early atherosclerosis in obese children.

Childhood obesity seems to contribute to the development and progression of early atherosclerosis, particularly in combination with insulin resistance. Our observations suggest that high insulin levels may have an important role in the pathogenesis of early atherosclerosis. According to our findings, the insulin indices derived from basal samples seem to be more useful for assessing subclinical atherosclerosis than indices obtained from OGTT, FSIVGTT, and clamp studies none of which are feasible in the pediatric age group.

\section{REFERENCES}

1. Wissler RW, Strong JP 1998 Risk factors and progression of atherosclerosis in youth: PDAY Research Group: Pathological Determinants of Atherosclerosis in Youth. Am J Pathol 153:1023-1033

2. Malcom GT, Oalmann MC, Strong JP 1997 Risk factors for atherosclerosis in young subjects: the PDAY Study: Pathobiological Determinants of Atherosclerosis in Youth. Ann N Y Acad Sci 817:179-188

3. Decsi T, Molnar D 2003 Insulin resistance syndrome in children: pathophysiology and potential management strategies. Paediatr Drugs 5:291-299

4. Galli-Tsinopoulou A, Karamouzis M, Arvanitakis SN 2003 Insulin resistance and hyperinsulinemia in prepubertal obese children. J Pediatr Endocrinol Metab 16:555560

5. Atabek ME, Pirgon O, Kurtoglu S 2006 Prevalence of metabolic syndrome in obese Turkish children and adolescents. Diabetes Res Clin Pract 72:315-321

6. Bonithon-Kopp C, Touboul P, Berr C, Leroux C, Mainard F, Courbon D, Ducimetiere P 1996 Relation of intima-media thickness to atherosclerotic plaques in the carotid arteries: the Vascular Aging (EVA) Study. Arterioscler Thromb Vasc Biol 16:310-316

7. Raitakari OT, Juonala M, Kahonen M, Taittonen L, Laitinen T, Maki-Torkko N, Jarvisalo MJ, Uhari M, Jokinen E, Ronnemaa T, Akerblom HK, Viikari JS 2003 Cardiovascular risk factors in childhood and carotid artery intima-media thickness in adulthood: the Cardiovascular Risk in Young Finns Study. JAMA 290:2277-2283

8. Burke GL, Evans GW, Riley WA, Sharrett AR, Howard G, Barnes RW, Rosamond W, Crow RS, Rautaharju PM, Heiss G 1995 Arterial wall thickness is associated with prevalent cardiovascular disease in middle-aged adults. The Atherosclerosis Risk in Communities (ARIC). Study. Stroke 26:386-391

9. Tonstad S, Joakimsen O, Stensland-Bugge E, Leren TP, Ose L, Russell D, Bonna KH 1996 Risk factors related to carotid intima-media thickness and plaque in children with familial hypercholesterolemia and control subjects. Arterioscler Thromb Vasc Biol 16:984-991

10. Atabek ME, Kurtoglu S, Demir F, Baykara M 2004 Relation of serum leptin and insulin-like growth factor-1 levels to intima-media thickness and functions of common carotid artery in children and adolescents with type 1 diabetes. Acta Paediatr 93:1052-1057

11. Jarvisalo MJ, Putto-Laurila A, Jartti L, Lehtimaki T, Solakivi T, Ronnemaa T, Raitakari OT 2002 Carotid artery intima media thickness in children with type 1 diabetes. Diabetes 51:493-498

12. Sorof JM, Alexandrov AV, Cardwell G, Portman RJ 2003 Carotid artery intimalmedial thickness and left ventricular hypertrophy in children with elevated blood pressure. Pediatrics 111:61-66

13. Tounian P, Aggoun Y, Dubern B, Varille V, Guy-Grand B, Sidi D, Girardet JP, Bonnet D 2001 Presence of increased stiffness of the common carotid artery and endothelial dysfunction in severely obese children: a prospective study. Lancet 358:1400-1404

14. Woo KS, Chook P, Yu CW, Sung RY, Qiao M, Leung SS, Lam CW, Metreweli C, Celermajer DS 2004 Overweight in children is associated with arterial endothelial dysfunction and intima-media thickening. Int J Obes Relat Metab Disord 28:852857

15. Zhu W, Huang X, He J, Li M, Neubauer H 2005 Arterial intima-media thickening and endothelial dysfunction in obese Chinese children. Eur J Pediatr 164:337-344

16. Balletshofer BM, Haap M, Rittig K, Stock J, Lehn-Stefan A, Haring HU 2005 Early carotid atherosclerosis in overweight non-diabetic individuals is associated with 
subclinical chronic inflammation independent of underlying insulin resistance. Horm Metab Res 37:331-335

17. Cole TJ, Bellizzi MC, Flega IK, Dietz WH 2000 Establishing a standard definition for child overweight and obesity worldwide: international survey. BMJ 320:12401243

18. Ueland PM, Refsum H, Stabler SP, Malinow MR, Andersson A, Allen RH 1993 Total homocysteine in plasma or serum: methods and clinical applications. Clin Chem 39:1764-1779

19. Matthews DR, Hosker JP, Rudenski AS, Naylor BA, Treacher DF, Turner RC 1985 Homeostasis model assessment: insulin resistance and beta-cell function from fasting plasma glucose and insulin concentrations in men. Diabetologia 28:412-419

20. Katz A, Nambi SS, Mather K, Baron AD, Follmann DA, Sullivan G, Quon MJ 2000 Quantitative insulin sensitivity check index: a simple, accurate method for assessing insulin sensitivity in humans. J Clin Endocrinol Metab 85:2402-2410

21. Matsuda M, DeFronzo RA 1999 Insulin sensitivity indices obtained from oral glucose tolerance testing-comparison with the euglycemic insulin clamp. Diabetes Care 22:1462-1470

22. Pignoli P, Tremoli E, Poli A, Oreste P, Paoletti R 1986 Intimal plus medial thickness of the arterial wall: a direct measurement with ultrasound imaging. Circulation 74:1399-1406

23. Srinivasan SR, Myers L, Berenson GS 1999 Temporal association between obesity and hyperinsulinemia in children, adolescents, and young adults: the Bogalusa Heart Study. Metabolism 48:928-934

24. Newman WP 3rd, Freedman DS, Voors AW, Gard PD, Srinivasan SR, Cresanta JL, Williamson GD, Webber LS, Berenson GS 1986 Relation of serum lipoprotein levels and systolic blood pressure to early atherosclerosis. The Bogalusa Heart Study. N Engl J Med 314:138-144

25. Ferrannini E, Buzzigoli G, Bonadonna R, Giorico MA, Oleggini M, Graziadei L, Pedrinelli R, Brandi L, Bevilacqua S 1987 Insulin resistance in essential hypertension. N Engl J Med 317:350-357
26. Invitti C, Guzzaloni G, Gilardini L, Morabito F, Viberti G 2003 Prevalence and concomitants of glucose intolerance in European obese children and adolescents. Diabetes Care 26:118-124

27. Ten S, Maclaren N 2004 Insulin resistance syndrome in children. J Clin Endocrinol Metab 89:2526-2539

28. Yeckel CW, Weiss R, Dziura J, Taksali SE, Dufour S, Burgert TS, Tamborlane WV, Caprio S 2004 Validation of insulin sensitivity indices from oral glucose tolerance test parameters in obese children and adolescents. J Clin Endocrinol Metab 89:10961101

29. Markus RA, Mack WJ, Azen SP, Hodis HN 1997 Influence of lifestyle modification on atherosclerotic progression determined by ultrasonographic change in the common carotid intima-media thickness. Am J Clin Nutr 65:1000-1004

30. Mayer EL, Jacobsen DW, Robinson K 1996 Homocysteine and coronary atherosclerosis. J Am Coll Cardiol 27:517-527

31. Duell PB, Malinow MR 1998 Homocyst (e) inemia and risk of atherosclerosis: clinical approach to evaluation and management. Endocrinologist 8:170-177.

32. Welch GN, Loscalzo J 1998 Homocysteine and atherothrombosis. N Engl J Med 338:1042-1050

33. Genest JJJr, McNamara JR, Upson B, Salem DN, Ordovas JM, Schaefer EJ, Malinow MR 1991 Prevalence of familial hyperhomocyst (e) inemia in men with premature coronary artery disease. Arterioscler Thromb 11:1129-1136.

34. Zhu W, Huang X, Li M, Neubauer H 2006 Elevated plasma homocysteine in obese schoolchildren with early atherosclerosis. Eur J Pediatr 165:326-331

35. Davis PH, Dawson JD, Riley WA, Lauer RM 2001 Carotid intimal-medial thickness is related to cardiovascular risk factors measured from childhood through middle age: the Muscatine study. Circulation 104:2815-2819

36. Mahoney LT, Burns TL, Stanford W, Thompson BH, Witt JD, Rost CA, Lauer RM 1996 Coronary risk factors measured in childhood and young adult life are associated with coronary artery calcification in young adults: the Muscatine Study. J Am Coll Cardiol 27:277-284 